\title{
Re-entitlement Effects with Duration Dependent Unemployment Insurance in a Stochastic Matching Equilibrium
}

\author{
Melvyn Coles, I.A.E. (ICREA) Adrian Masters, SUNY Albany*
}

November 2005

\begin{abstract}
In the context of a standard equilibrium matching framework, this paper considers how a duration dependent unemployment insurance (UI) system affects the dynamics of unemployment and wages in an economy subject to stochastic job-destruction shocks. It establishes that re-entitlement effects induced by a finite duration UI program generate intertemporal transfers from firms that hire in future booms to firms that hire in current recessions. These transfers imply a net hiring subsidy in recessions which stabilizes unemployment levels over the cycle.
\end{abstract}

JEL \# J63, J64, J65, E32..

Keywords: Matching frictions, Unemployment, Duration Dependent UI.

${ }^{*}$ Corresponding Author: Adrian Masters, Department of Economics, SUNY Albany, 1400 Washington Avenue, Albany, NY 12222, USA. amasters@albany.edu 


\section{Introduction}

This paper considers a matching equilibrium where the aggregate economy is subject to stochastic job-destruction shocks. Workers when laid off are entitled to unemployment benefits for a fixed term, say 6 months, after which they receive no further benefits from the government. Since Mortensen [1977] we know that such duration dependent unemployment benefit schemes generate re-entitlement effects: becoming re-employed implies the worker (eventually) requalifies for full unemployment insurance (UI). This paper considers the impact of such re-entitlement effects on hiring incentives over a (stochastic) business cycle. We show that in a non-competitive labour market, re-entitlement effects generate an intertemporal transfer from future hiring firms to current hiring firms. Such transfers are employment stabilising over the cycle - they imply a net hiring subsidy in recessions.

An important insight for our results is that in a non-competitive labour market, the joint value of a worker-firm match is increasing in the level of UI benefits. This occurs because the UI system credibly raises the worker's reservation wage when laidoff which subsequently forces the worker's next employer to offer a higher hiring wage. By extracting more rents from an outside party (the next hiring firm) the UI system increases the joint value of a current match. The issue then is who enjoys those additional rents? Clearly if the worker has all the bargaining power, those rents go into the worker's pocket and the current employer does not benefit. Less obviously, those rents also go into the worker's pocket if UI payments are constant with duration. In that case increasing the level of UI payments is not unlike increasing the value of leisure while unemployed. This automatically leads to higher negotiated wages and

all firms are worse off. But suppose instead UI payments are duration dependent - for example suppose UI payments cease after 6 months unemployment. This introduces re-entitlement effects - the unemployed worker whose UI entitlement has expired can only become re-entitled to future UI through re-employment. Re-entitlement effects allow the current hiring firm to expropriate at least part of those third party rents. 
The mechanism is most easily understood by assuming firms have all the bargaining power and so hire unemployed workers at their reservation wage. In that case unemployed workers never obtain any surplus from re-employment - each worker is always just indifferent to accepting a job offer. Consider then an unemployed worker whose UI entitlement has expired. By becoming employed, this worker becomes entitled to UI in the future when laid off. But the hiring firm (who has all the bargaining power) extracts those entitlement rents through a lower wage. Now consider what happens when that worker is laid off at some future (random) date because of a job destruction shock. UI entitlement implies a worker has a higher reservation wage which forces a future hiring firm to offer a more generous wage (should the worker get a job before his UI entitlement expires). But that surplus was fully extracted by the original hiring firm through a lower hiring wage. Thus re-entitlement effects imply a transfer of rents from the (as yet unknown) future hiring firm to current hiring firms.

Such re-entitlement effects do not necessarily reduce unemployment. When a firm hires a worker who is entitled to receive further UI, the higher wage that needs to be offered is essentially a transfer to the worker's previous employer. [That employer paid a lower wage reflecting this potential outcome]. Of course by becoming fully reentitled to UI in the future, the current firm offers a lower wage reflecting those future rents. But discounting implies those expected future rents are valued less than the current (average) loss and equilibrium may yield higher steady state unemployment.

Outside of steady state the analysis is more complicated. The paper identifies this transfer effect using a standard equilibrium matching framework where firms are subject to idiosyncratic job destruction shocks which evolve stochastically over time. In the Conclusion we provide a back-of-the-envelope calculation for the U.S. economy which suggests that the net transfer to firms hiring in recessions may be as high as 6 weeks UI. This works out as a $1.5 \%$ wage subsidy. This is clearly not a huge amount but being a targeted hiring subsidy it yields a significant stabilising 
effect on employment over the cycle. Simulations formally establish that a reduction in the duration of UI (tied to a compensating increase in the level of benefits so that the budget balancing tax is held constant) implies a reduction both in the average unemployment level and in the variance of unemployment over time.

The existing literature on duration dependent UI systems has several strands. The optimal UI literature (e.g. Shavell and Weiss [1979], Hopenhayn and Nicolini [1997]) designs UI programs which insure employed workers against layoff risk. There are no re-entitlement effects in those papers as they consider an individual looking for work during a single spell of unemployment.

Using a sequential search framework Mortensen [1977] and van den Berg [1990] ask how a duration dependent UI program affects reservation wages given an exogenous distribution of wages. Those papers show that the re-entitlement effect reduces reservation wages at long unemployment durations. Albrecht and Vroman [2005] extend that approach by instead supposing UI payments expire according to a Poisson process (rather than after a deterministic period of time). This simpler framework allows them to identify a steady state wage posting equilibrium. Equilibrium is characterised by a two point wage distribution where workers whose UI payments have expired have a lower reservation wage. As this reservation wage depends on re-entitlement effects, re-entitlement effects lead to lower posted wages.

Perhaps the closest literature is the equilibrium matching literature with duration dependent UI. This literature has two strands. Millard and Mortensen [1997], Davidson and Woodbury [1997], Fredriksson and Holmlund [2001], Cahuc and Lehmann [2001], Coles [2005] suppose wages are determined by Nash bargaining where the worker's threatpoint is the value of being laid-off. This bargaining approach much simplifies the analysis as it implies all workers negotiate the same wage. Assuming workers are strictly risk averse, these papers then consider the optimal (duration dependent) UI program taking into account that the UI program distorts wages and hence job creation rates by firms. Note however that this Nash bargaining approach 
rules out any re-entitlement effects on wages - although unemployed workers whose UI payments have expired have low reservation wages, they negotiate the same high wage consistent with being fully entitled to receive UI. ${ }^{1}$ Perhaps Cahuc and Lehmann [2001] provide the best motivation for this approach - they assume union wage bargaining where wages are negotiated by insiders (whose threatpoint is the value of being laid-off) and new employees (outsiders) must be hired at the union wage. Coles and Masters [2004,2005] instead assume hiring wages are determined by strategic bargaining between the hiring firm and the unemployed worker and so depend on the worker's remaining entitlement to further UI. The bargaining approach used here is closely related. Coles and Masters [2005] show that for sensible parameter values, UI payments around the one-year duration mark distort (average) hiring wages the most. With the exception of Millard and Mortensen [1997], the above papers only consider steady state and so do not identify the stabilisation mechanism identified in this paper. Millard and Mortensen [1997] assume Nash bargaining which rules out re-entitlement effects on wages.

Following Mortensen and Pissarides [1994] there is also a rapidly growing literature which describes equilibrium matching when the economy is subject to aggregate productivity shocks. The aim of this literature is to determine whether this matching approach can fit the business cycle data. Shimer [2005] argues that the standard Nash bargaining approach implies wages are too procyclical. The resulting variation of vacancies over the cycle is then too small. This occurs as the assumed worker bargaining threatpoint - the value of being unemployed - moves a lot over the cycle. Of course it is well known that different bargaining games imply different Nash bargaining structures (e.g. Binmore, Rubinstein and Wolinsky [1986]). For example if search is costly and so while bargaining the worker does not search for outside opportunities (the worker expects to reach immediate agreement tomorrow and so there is little gain to search), the worker's equilibrium threatpoint while bargaining is simply

\footnotetext{
${ }^{1}$ but note that re-entitlement effects encourage greater search effort by the unemployed
} 
the value of leisure. This immediately implies wages move less over the cycle (e.g. Hall and Milgrom [2005]). Our bargaining approach is closely related to this latter approach - the unemployed worker's threatpoint here is not the value of continued search, it is the value of leisure augmented by additional UI payments received from the government (if entitled). See Mortensen and Nagypal [2005] for a mini survey of this rapidly burgeoning literature.

Finally it is worth pointing out that the wage effects considered here are not unrelated to the on-the-job search approach (e.g. Postel-Vinay and Robin [2002a,b] and Cahuc, Postel-Vinay and Robin [2005]) and the investment literature (Acemoglu [1997], Acemoglu and Pischke [1999]. In the on-the-job search approach, an employed worker can obtain outside job offers which trigger Bertrand competition between his current employer and the outside firm. Such competition yields significant wage increases. When hiring an unemployed worker, the hiring firm offers a low starting wage reflecting these expected future wage gains. The same mechanism occurs here where re-entitlement to UI implies the worker can extract more rents from the next hiring firm and so the current hiring firm extracts those rents through offering a lower wage. Acemoglu [1997] points out that with job destruction shocks, ex-post wage bargaining implies the worker's next employer will extract part of the rents which accrue to general human capital investment. As that employer is not identified at the time when training takes place, this market failure leads to too little training. Our point is that a UI system generates the opposite transfer effect. Should the worker be laid off in the future, then being entitled to receive UI payments increases the worker's reservation wage when next employed, and the worker extracts greater rents from his next future employer. 


\section{The Model.}

Time is continuous and has an infinite horizon. There is a continuum of identical workers with mass normalized to one, and all workers are infinitely lived. Each worker may be in one of two states, employed or unemployed, where $U_{t}$ denotes the measure of workers unemployed at time $t$. There is also a continuum of vacancies with measure $V_{t}$ which will be determined endogenously via a standard free entry condition.

There are matching frictions where a matching function $M_{t}=M\left(U_{t}, V_{t}\right)$ describes the contact rate between the unemployed job seekers and the firms holding vacancies. $M$ is strictly increasing in both arguments, continuous, concave and homogenous of degree 1 with $M(0, V)=M(U, 0)=0$ and $M_{V}(U, 0)=\infty$ for $U>0 . \theta_{t}=V_{t} / U_{t}$ denotes labor market tightness at time $t$. For $d t$ arbitrarily small, the probability an unemployed worker contacts a vacancy over time interval $[t, t+d t)$, denoted $\alpha_{w}(t) d t$, is given by

$$
\alpha_{w}=\frac{1}{U_{t}} M\left(U_{t}, V_{t}\right)=M\left(1, \frac{V_{t}}{U_{t}}\right) \equiv m\left(\theta_{t}\right)
$$

and $m$ is a strictly increasing, concave function of $\theta$ with $m(0)=0, m^{\prime}(0)=\infty$. Similarly, the probability a vacancy is contacted by a searching worker over time interval $[t, t+d t)$, denoted $\alpha_{f}(t) d t$,is given by

$$
\alpha_{f}=\frac{1}{V_{t}} M\left(U_{t}, V_{t}\right)=\frac{U_{t}}{V_{t}} M\left(1, \frac{V_{t}}{U_{t}}\right) \equiv \frac{m\left(\theta_{t}\right)}{\theta_{t}} .
$$

For simplicity, all are risk neutral and have the same discount rate $r$. If a worker is employed at wage $w$, and employment is taxed at rate $\tau$ by the government, then the employee receives utility $w d t$ per instant $d t$, the firm obtains net profit $(p-w-\tau) d t$ and $\tau d t$ is tax revenue collected per employed worker. Note, all firms are equally productive and $p$ does not vary over time. There is no on-the-job search - a worker must quit before searching for alternative employment.

There are idiosyncratic job destruction shocks, where each job is destroyed according to an independent Poisson process with parameter $\lambda_{t}>0$, where $\lambda_{t}$ describes the 
aggregate rate of job destruction at time $t . \lambda_{t}$ evolves according to an N-state Markov process: $\lambda_{t}$ can take one of $N$ values $\lambda^{i}$, where $0<\lambda^{1}<\lambda^{2}<. .<\lambda^{N}$. Given $\lambda_{t}=\lambda^{i}$, $\lambda_{t}$ switches state according to a Poisson process with parameter $\gamma>0$, whereupon the new realized job destruction state is $\lambda^{j}$ with probability $\pi^{j}$. Assume that when a job is destroyed, the worker is laid off and becomes unemployed.

The unemployment insurance system (UI) is described by a benefit function $b($.$) ,$ where $b(s) d t$ describes the benefit paid over instant $d t$ to a worker who has unemployment duration $s$, and an employment $\operatorname{tax} \tau$. Note, the benefit profile $b($.$) and tax$ rate $\tau$ do not vary over the cycle. More generally, these policy parameters could vary with time and be conditioned on the state of the economy. Assuming the scheme is fixed over the cycle, however, is empirically realistic and allows us to assess how such schemes stabilize unemployment. $b($.$) is positive and non-increasing with du-$ ration and a worker obtains flow value $l>0$ while unemployed. Further assume $b(0)+l<p-\tau$ so that a gain to trade always exists and so (efficient) bargaining implies that any contact between a vacancy and an unemployed worker always results in a match. Given $b($.$) , the employment tax \tau$ has to ensure (long run) budget balance; i.e. the expected discounted revenues from the employment tax must equal the expected discounted benefits paid. Hence, on average, $\tau$ describes a fair insurance premium. $^{2}$

Given that all jobs are equally likely to be destroyed, assume that the UI program provides universal coverage - that each worker when laid-off through job destruction returns to the pool of unemployed workers with duration $s=0$. Real world systems do not usually re-entitle workers to full coverage as soon as they get rehired. Both duration and generosity of entitlement are usually a complicated function of the worker's recent labor market history (see OECD [2004]). But as the average duration of employment is 4.5 years in the US (Cole and Rogerson [1999]), which is much longer

\footnotetext{
${ }^{2} \mathrm{~A}$ technical issue here is that recessions could last so long that debt repayment would exceed the total output of the economy. One way to avoid this problem would be to sell the financing of the scheme to an organization with deep pockets.
} 
than standard qualification periods, this immediate re-entitlement assumption is not unreasonable. ${ }^{3}$ Assume also that only workers who have been laid off are entitled to receive UI payments - workers who quit receive nothing.

Let $F_{t}(s)$ denote the proportion of unemployed workers at time $t$ whose current unemployment spell is no greater than $s$. As negotiated wages generally depend on a worker's unemployment duration $s$, the equilibrium rate of job creation at time $t$ depends on $F_{t}$. As the value of being unemployed depends on (future) job creation rates, it will depend on how $F_{t}$ evolves stochastically over time. Unfortunately $F_{t}$ is infinitely dimensional which makes the characterisation of equilibrium problematic.

Tractability requires assuming that either workers or firms make take-it-or-leaveit wage offers. ${ }^{4}$ As giving workers all the bargaining power is uninteresting (firms never make any profit and so never invest in vacancies), we assume firms have all the bargaining power. Li and Wright [1998] make the same simplifying assumption in a non-steady-state money search equilibrium. ${ }^{5}$ As unmatched workers never obtain any surplus through re-employment, worker value functions are trivial to compute. Characterising equilibrium then reduces to characterising optimal vacancy creation rates given firms extract all surplus. A minor drawback of this simplifying assumption is that workers are best off when just laid-off, which is unrealistic. This outcome

\footnotetext{
${ }^{3}$ For a new entrant to the labor market, the longest qualification period of employment for full entitlement is 2 years (UK). Most systems provide at least partial coverage after much shorter periods of contributions. Furthermore, most people getting hired are not new entrants. Most have some history of employment within the qualifying period which speeds up their re-entitlement to benefits.

${ }^{4}$ The difficulty is that the joint value of the match depends on the value of the worker's reentitlement to full UI coverage. In general this depends on re-employment rates when the worker is laid-off (at some future random date). Those rates in a free entry vacancy creation equilibrium depend on $F_{t}($.$) which is infinitely dimensional. Hence, in general, today's negotiated wage depends$ on how (infinitely dimensional) $F_{t}$ is expected to evolve in the future. Giving firms all the bargaining power neatly sidesteps this issue.

${ }^{5}$ also see Cahuc, Postel-Vinay and Robin (2005) which estimates a structural model of the French labour market and finds that for most occupations the firm's bargaining power is close to one.
} 
would not occur if workers had all the bargaining power - workers would then earn wage $w=p$ while employed and obtain $l+b(s)<p$ while unemployed. We believe our insights on re-entitlement effects are robust to giving workers positive bargaining power - unfortunately we cannot demonstrate this formally. A different potential criticism of this result is that employed workers would renegotiate as the value of being laid-off exceeds the value of being employed. Such an argument however ignores the relevant worker threatpoint when renegotiating. It is not typically the case that a worker can claim UI payments while re-negotiating - the worker is on strike, not laid-off. Similarly if the worker threatens to quit if the wage is not renegotiated - a worker is only entitled to UI payments if laid-off. A property of our equilibrium is that a worker is always better off remaining employed at the negotiated wage than quitting into unemployment with no UI support (or going on strike). Indeed we need to assume that when a firm hires a worker, they write an enforceable contract which states that the worker earns some fixed wage $w$ until job destruction occurs. It is interesting that this wage contract protects the worker's interests. Specifically the firm would like to renegotiate ex-post, driving the wage down to the point where the worker is indifferent to quitting. The worker instead enforces the terms of the contract.

Following Pissarides [2000] we assume a firm must pay a flow cost $a d t>0$ per instant $d t>0$ to advertise a vacancy. If the firm does not advertise, its contact

probability is zero. With free entry, the number of vacancies adjusts so that the expected discounted value of advertising is zero.

\section{Characterizing Equilibrium.}

In general the relevant aggregate state variable at time $t$ is $\phi_{t}=\left(U_{t}, F_{t}, \lambda_{t}\right)$. Let $V_{u}\left(s, \phi_{t}\right)$ denote the value of being unemployed in state $\phi_{t}$ with unemployment duration $s \geq 0$. As firms have all the bargaining power, a worker with unemployment 
duration $s$ in state $\phi_{t}$ is hired with an employment contract which has value equal to $V_{u}\left(s, \phi_{t}\right)$. Hence the recursive Bellman equation describing $V_{u}$ over arbitrarily small interval $d t>0$ is

$$
V_{u}\left(s, \phi_{t}\right)=\frac{1}{1+r d t}\left[[l+b(s)] d t+E_{t} V_{u}\left(s+d t, \phi_{t+d t}\right)\right]
$$

where the worker obtains flow payoff $[l+b(s)] d t$ over the next instant, and obtains payoff $V_{u}\left(s+d t, \phi_{t+d t}\right)$ from then on, regardless of whether the worker receives a job offer or not. The value of being unemployed is therefore the expected discounted value of being unemployed forever. As by assumption UI payments are independent of $\phi_{t}$ then, with a slight abuse of notation, the value of being unemployed is simply

$$
V_{u}(s)=\int_{s}^{\infty} e^{-r(x-s)}[l+b(x)] d x=l / r+B(s),
$$

where

$$
B(s)=\int_{s}^{\infty} e^{-r(x-s)} b(x) d x
$$

is the worker's option value of consuming his/her remaining UI entitlement at duration $s$. It is now straightforward to compute equilibrium.

\subsection{Equilibrium Wage Formation}

Consider the value of being employed on wage contract $w$ in state $\phi_{t}$. Should a job

destruction shock occur, the worker is laid off and obtains payoff $V_{u}(0)$ as described above. As the wage paid is constant over time, the value of the worker's employment contract depends only on $\phi_{t}$ via the current job destruction rate $\lambda_{t}$. Let $V_{e}^{i}(w)$ denote the value of being employed on wage contract $w$ in job destruction state $i$. Standard arguments imply

$$
r V_{e}^{i}(w)=w+\lambda^{i}\left[V_{u}(0)-V_{e}^{i}(w)\right]+\gamma \sum_{j} \pi^{j}\left[V_{e}^{j}(w)-V_{e}^{i}(w)\right]
$$


where the worker obtains flow utility $w$ while employed, is laid off at rate $\lambda^{i}$ in state $i$, and the economy switches state at rate $\gamma$. Putting $i=1$ implies

$$
\left(r+\lambda^{1}+\gamma\right) V_{e}^{1}(w)=w+\lambda^{1} V_{u}(0)+\gamma \sum_{j} \pi^{j} V_{e}^{j}(w)
$$

and substituting out $w$ using the previous equation yields

$$
\left(r+\lambda^{1}+\gamma\right) V_{e}^{1}(w)-\left(r+\lambda^{i}+\gamma\right) V_{e}^{i}(w)=\left(\lambda^{1}-\lambda^{i}\right) V_{u}(0)
$$

Rearrange this equation for $V_{e}^{i}(w)$ in terms of $V_{e}^{1}(w)$. Using that expression to substitute out the $V_{e}^{j}(w)$ in the top equation and then solving for $V_{e}^{1}$ implies the following.

Lemma 1. For $i=1, . ., N$,

$$
V_{e}^{i}(w)=\frac{w+\bar{\lambda}^{i} V_{u}(0)}{r+\bar{\lambda}^{i}}
$$

where

$$
\bar{\lambda}^{i}=\lambda^{i}-\sum_{j} \pi^{j} \frac{\gamma}{r+\lambda^{j}+\gamma}\left(\lambda^{i}-\lambda^{j}\right) .
$$

If job destruction rates did not switch over time, i.e. if $\gamma=0$, then $\bar{\lambda}^{i}=\lambda^{i}$ and the solution above simplifies to the more recognizable form $V_{e}^{i}=\left(w+\lambda^{i} V_{u}(0)\right) /(r+$ $\left.\lambda^{i}\right)$. Stochastic job destruction rates, however, imply $\bar{\lambda}^{i}$ reflects that with positive probability the economy will switch to a different job destruction state in the future. Note the above implies $\bar{\lambda}^{1}>\lambda^{1}$, reflecting that job destruction rates will be higher in the future. Also note that $\lambda^{k}>\lambda^{i}$ implies $\bar{\lambda}^{k}>\bar{\lambda}^{i}$.

As firms have all the bargaining power, the negotiated wage is set where the worker is indifferent to accepting employment. Given a worker with unemployment duration $s$ and in job destruction state $i$, the equilibrium negotiated wage $w=w^{i}(s)$ satisfies

$$
V_{e}^{i}(w)=V_{u}(s)
$$

Solving this equation using (1) and (3) implies the following.

Proposition 1. Equilibrium Wages 
Given unemployment duration $s$ and job destruction state $i$, the equilibrium wage agreement $w^{i}(s)$ is

$$
w^{i}(s)=l+r B(s)-\bar{\lambda}^{i}\left[V_{u}(0)-V_{u}(s)\right]
$$

Equilibrium wages are composed of three terms: the wage compensates for foregone leisure, the option value of foregone UI payments at the point of hire (appropriately annuitised) and there is a wage deduction which takes into account the value of becoming re-entitled to full UI coverage in the event of a future job destruction shock. Section 4 discusses this wage equation in detail and the reader who is familiar with the equilibrium matching approach (e.g. Pissarides [2000]) might skip to that section. In the rest of this section we complete the description of equilibrium.

\subsection{Equilibrium Vacancy Creation.}

Let $\Pi^{i}(w)$ denote the firm's expected discounted profit with contracted wage $w$ in job destruction state $i$. As a free entry equilibrium implies the firm makes zero profit if the job is destroyed, then standard arguments imply

$$
r \Pi^{i}(w)=[p-w-\tau]+\lambda^{i}\left[0-\Pi^{i}(w)\right]+\gamma \sum_{j} \pi^{j}\left[\Pi^{j}(w)-\Pi^{i}(w)\right] .
$$

Using the same method as before yields

$$
\Pi^{i}(w)=\frac{p-w-\tau}{r+\bar{\lambda}^{i}}
$$

Not surprisingly $\lambda^{k}>\lambda^{i}$ implies $\Pi^{k}(w)<\Pi^{i}(w)$; filled jobs are less valuable in high job destruction states.

Proposition 2. Equilibrium Job Creation.

In state $\phi_{t}$ with $\lambda_{t}=\lambda^{i}$, free entry of vacancies implies equilibrium labor market tightness $\theta_{t}=\theta\left(\phi_{t}\right)$ defined by the implicit function:

$$
a=\frac{m(\theta)}{\theta} \int_{0}^{\infty} \Pi^{i}\left(w^{i}(s)\right) d F_{t}(s)
$$


Proof: Given $\lambda_{t}=\lambda^{i}$ and contact with an unemployed worker with unemployment duration $s$, the firm negotiates a labor contract with equilibrium wage $w^{i}(s)$ described by Proposition 1. This generates expected discounted profit $\Pi^{i}\left(w^{i}(s)\right)$. Given the distribution of uncompleted spells of unemployment $F_{t}$, free entry of vacancies implies the flow cost of creating a vacancy equals the expected gain through contacting a currently unemployed job seeker, where $m(\theta) / \theta$ describes the instantaneous contact rate given labor market tightness $\theta$.

Having described equilibrium wage formation and equilibrium market tightness, the description of the equilibrium market dynamics $\phi_{t}$ is now straightforward.

\subsection{Equilibrium Market Dynamics}

Given $\phi_{t}$, unemployment at time $t$ evolves according to the differential equation

$$
\frac{d U_{t}}{d t}=\lambda_{t}\left(1-U_{t}\right)-m\left(\theta_{t}\right) U_{t}
$$

where the first term on the right hand side describes the inflow of workers into unemployment through job destruction, while the second describes the outflow through matching.

Given $\phi_{t}$ and for $d t>0$ but arbitrarily small, the distribution of unemployment spells $F_{t}$ evolves according to

$$
U_{t+d t} F_{t+d t}(s)=\left[1-m\left(\theta_{t}\right) d t\right] U_{t} F_{t}(s-d t)+\lambda^{i} d t\left[1-U_{t}\right]+o(d t)
$$

where the left hand side describes the number of unemployed workers at date $t+d t$ with unemployment duration no greater than $s$, which equals the number unemployed in the previous instant with duration no more than $s-d t$ and who failed to get a job over that instant, plus those employed who lost their job and so entered the pool of unemployed workers with duration $s=0$. Taking the limit $d t \rightarrow 0$ and using the above solution for $d U_{t} / d t$ implies $F_{t}$ evolves over time according to the differential equation

$$
\frac{\partial F_{t}(s)}{\partial t}=\lambda_{t} \frac{1-U_{t}}{U_{t}}\left[1-F_{t}(s)\right]-\frac{\partial F_{t}(s)}{\partial s} .
$$


Given an initial distribution of unemployment spells, $F_{0}(s)$, initial level of unemployment $U_{0}$ and the Markov process describing $\lambda_{t}$, these two differential equations, together with Proposition 2 describing $\theta_{t}$, imply a first order Markov process for $\phi_{t}=\left\{U_{t}, F_{t}, \lambda_{t}\right\}$.

Finally given the UI profile $b($.$) and the initial state of the economy \left(U_{0}, F_{0}, \lambda_{0}\right)$, the employment tax rate $\tau$ has to achieve long run budget balance. Given the above Markov process for $\phi_{t}$, this requires:

$$
E_{0} \int_{0}^{\infty} e^{-r t}\left[\left(1-U_{t}\right) \tau-U_{t} \int_{0}^{\infty} b(s) d F_{t}(s)\right] d t=0 .
$$

\subsection{Existence of a Market Equilibrium.}

When $\lambda^{i}=\lambda$ for all $i$ and for a constant UI program $b(s)=\bar{b}$ for all $s$, it is straightforward to show that a steady state equilibrium exists if $\bar{b}$ is small enough. In fact Coles and Masters [2004] establish that if one equilibrium exists, then generically there are two. That paper identifies such equilibria by first fixing an arbitrary value for $\tau$ and solving for steady state labour market tightness, denoted $\theta^{*}(\tau)$, and unemployment level $U^{*}(\tau)$. Budget balance then requires identifying a tax rate $\tau$ satisfying

$$
\tau\left[1-U^{*}(\tau)\right]=\bar{b} U^{*}(\tau)
$$

For Laffer curve reasons, either budget balance is not possible (benefits $\bar{b}$ are too high to be fully funded) or there are two tax rates which achieve budget balance. Not surprisingly the equilibria are Pareto rankable, where the equilibrium with the lower tax rate and higher employment level is preferred.

The same existence argument applies to the stochastic structure described above. For given benefit profile $b($.$) and initial values U_{0}, F_{0}, \lambda_{0}$, fix an arbitrary tax rate $\tau$. Equation (6) describes equilibrium profits $\Pi^{i}$ which are continuous in $\tau$. Hence for given $\phi_{t}$, Propositions 1 and 2 imply that the aggregate vacancy creation decision, which determines equilibrium labor market tightness $\theta_{t}$, is continuous in $\tau$. Hence the differential equations describing the evolution of $U_{t}, F_{t}, \lambda_{t}$ are continuous in $\tau$ and so 
given $\left(U_{0}, F_{0}, \lambda_{0}\right)$, the expected discounted tax returns and benefit payments are also continuous in $\tau$. The Laffer curve argument now goes through: $\tau=0$ implies zero tax revenues, while $\tau=p-l$ implies no vacancy creation. Hence the budget surplus is hump-shaped in $\tau$, and typically there is either no tax rate which achieves budget balance, or there will be at least two. Obviously the lowest tax rate which achieves budget balance is preferred.

\section{Discussion and Simulations}

\subsection{Intergenerational Transfer of Rents}

A primary insight of this framework is that with non-competitive wage formation, the UI system transfers rents from future employers to current matched firm/worker pairs. The point is made most readily in the steady state case $\left(\lambda^{i}=\lambda\right.$ for all $i$ and $\alpha_{w}$ constant). In that case, Proposition 1 implies an unemployed worker with duration $s$ negotiates wage

$$
w(s)=l+r B(s)-\lambda\left[V_{u}(0)-V_{u}(s)\right] .
$$

The worker extracts rents $B(s)$ reflecting the worker's option value of consuming his/her remaining UI entitlement, while the firm extracts the surplus attached to becoming re-entitled to full UI coverage in the future.

It is useful to decompose $V_{u}(0)$, which is the expected discounted lifetime utility of a worker with unemployment duration $s=0$, as

$$
V_{u}(0)=\int_{0}^{\infty} e^{-r x}\left\{e^{-\alpha_{w} x}\left[l+b(x)+\alpha_{w} V_{u}(x)\right]\right\} d x .
$$

where with probability $e^{-\alpha_{w} x}$ the worker remains unemployed at duration $x$ and so receives flow utility $[l+b(x)] d x$ over the next instant, and with probability $e^{-\alpha_{w} x} \alpha_{w} d x$ finds work at that duration with expected payoff $V_{e}=V_{u}(x) .{ }^{6}$ This expression decom-

${ }^{6}$ One way to derive this equation is to note that $V_{u}($.$) satisfies the differential equation$

$$
r V_{u}-\frac{d V_{u}}{d s}=l+b(s)+\alpha_{w}\left[V_{e}-V_{u}\right]
$$


poses $V_{u}(0)$ into expected UI payments received from the government, and expected rents extracted from the worker's next employer.

Now fair insurance in a steady state implies

$$
\tau=\lambda \int_{0}^{\infty} e^{-r x}\left[e^{-\alpha_{w} x} b(x) d x\right]
$$

where the integral term computes the expected discounted UI payments made to a worker who is laid-off. As $V_{u}(x) \equiv l / r+B(x)$, the above decomposition of $V_{u}(0)$ simplifies to

$$
V_{u}(0)=\frac{l}{r}+\frac{\tau}{\lambda}+\int_{0}^{\infty} e^{-\left(r+\alpha_{w}\right) x} \alpha_{w} B(x) d x .
$$

It is convenient to denote the last term as

$$
R=\int_{0}^{\infty} e^{-\left(r+\alpha_{w}\right) x} \alpha_{w} B(x) d x .
$$

which describes the expected rents extracted from the next employer by a laid-off worker. Using (10) and $V_{u}(s)=l / r+B(s)$ in (8) now implies

$$
w(s)=l-\tau+(r+\lambda) B(s)-\lambda R,
$$

which makes explicit the intergenerational transfer of rents across firms. When hiring a worker, who becomes re-entitled to full UI coverage, the firm pays a lower wage reflecting the rents the worker will extract from his/her next employer in the event of a job destruction shock (which occurs at rate $\lambda$ ). The firm, however, also has to pay a wage premium to compensate the worker for his/her option value of continued UI (which has value $B(s)$ and is appropriately annuitised). Of course those rents were appropriated by the worker's previous employer. The UI system therefore implies a transfer of rents from future hiring firms to current hiring firms. Also note that where $V_{e}(s)$ is the value of becoming employed at duration $s$. Hence

$$
\left(r+\alpha_{w}\right) V_{u}-\frac{d V_{u}}{d s}=l+b(s)+\alpha_{w} V_{e}
$$

Integration using integrating factor $e^{-\left(r+\alpha_{w}\right) s}$ implies the form stated, where $V_{e}(s)=V_{u}(s)$ when firms have all the bargaining power. 
the worker pays the insurance tax $\tau$ (but is fully compensated by expected future UI receipts when laid-off).

Note that the joint value of the match is

$$
\frac{p-\tau-w}{r+\lambda}+\left[\frac{w+\lambda V_{u}(0)}{r+\lambda}-\frac{l}{r}\right]=\frac{p-l}{r+\lambda}+\frac{\lambda}{r+\lambda} R
$$

which is directly proportional to $R$. By extracting more rents from a third party (the worker's next employer) the UI system increases the joint value of any given match.

Given these rent transfer effects, it is useful to consider how they affect the expected value of filling a vacancy. As steady state implies unemployment spell distribution $d F(s)=\alpha_{w} e^{-\alpha_{w} s} d s$, then given $w(s)$ described above, the expected profit by filling a vacancy

$$
\int_{0}^{\infty} \frac{p-w(s)-\tau}{r+\lambda} d F(s)=\frac{p-l}{r+\lambda}-\int_{0}^{\infty}\left[1-\frac{\lambda e^{-r s}}{r+\lambda}\right] B(s) d F(s) .
$$

Note, $r>0$ implies the UI system reduces the expected value of filling a vacancy in a steady state; the expected rents lost to new hires exceeds the (discounted) value of extracting rents from the worker's next employer. More generous UI payments leads, in a steady state, to lower expected profit per filled vacancy and hence lower vacancy creation rates and higher unemployment.

This result, however, needs to be interpreted with care as it ignores non-steady state dynamics. For example, suppose the economy begins life with all workers unemployed and none entitled to receive UI. As firms have all the bargaining power, these workers obtain no surplus by finding work. Assuming the economy converges to a steady state, then any rents lost by firms in that steady state must have been appropriated by previous employers. Hence outside of steady state, the UI scheme allows the early hiring firms to extract rents from later firms. Such transfers imply high initial vacancy creation rates and a more rapid decline in unemployment over time. It is precisely this mechanism which stabilizes unemployment levels over the cycle. 
Finally note that the rent extraction term, $R=\int_{0}^{\infty} e^{-\left(r+\alpha_{w}\right) x} \alpha_{w} B(x) d x$, is strictly increasing in the re-employment rate $\alpha_{w}$. To see this, note that $\alpha_{w} e^{-\alpha_{w} s}$ is the density function corresponding to the exponential distribution and that a lower $\alpha_{w}$ implies first order stochastic dominance. As $e^{-r s} B(s)$ is decreasing in $s$, then (11) implies a lower $\alpha_{w}$ yields a lower $R$. The intuition is that when laid off, a lower $\alpha_{w}$ implies the worker expects to be unemployed longer and so expects a smaller remaining entitlement $B($.$) at the point of hire. Further the longer duration implies those$ rents are discounted more. This insight plays an important part in the simulations that follow - firms that hire in booms (characterized by high re-employment rates and short unemployment spells) lose more rents to unemployed workers which, by forward looking bargaining, are implicitly an employment subsidy paid to the worker's previous employer.

\subsection{Employment Stabilization over the Cycle.}

With duration dependent UI, Proposition 1 and (6) imply the firm makes expected profit

$$
E_{t}\left[\Pi^{i}\left(w^{i}(s)\right)\right]=\frac{p-l}{r+\bar{\lambda}^{i}}-\int_{0}^{\infty} B(s) d F_{t}(s)+\frac{\bar{\lambda}^{i} V_{u}(0)-\tau}{r+\bar{\lambda}^{i}},
$$

by hiring a worker at time $t$ in state $i$. Note, the firm loses rents $B(s)$ by hiring a worker with unemployment duration $s$, but gains expected surplus $\bar{\lambda}^{i} V_{u}(0)-\tau$ through re-entitlement effects. The previous section established that in a steady state with $\lambda^{i}=\lambda$, discounting implies the the expected loss $\int_{0}^{\infty} B(s) d F(s)$ dominates the reentitlement effect. This is not necessarily the case outside of a steady state. In particular the UI scheme raises the expected value of filling a job in the recession if

(i) the currently unemployed have relatively long unemployment spells, i.e. $d F_{t}(s)$ has more weight at long durations $s$. In that case, fewer rents are extracted by the currently unemployed, and

(ii) hiring rates are expected to be higher in the future, so that future hiring firms bear more of the cost of providing the laid-off worker payoff $V_{u}(0)$. 
We now use a numerical simulation to establish formally that a duration dependent UI system lowers both the mean and the variance of unemployment levels over the cycle.

\subsection{A Simulation.}

Consider an economy whose welfare system is composed of two schemes: (i) a 6-month UI scheme, which pays $b(s)=b_{U I}$ for unemployment durations $s$ below 6 months, and (ii) a UA (unemployment assistance) scheme which pays $b_{U A}$ to workers whose UI entitlement has expired; i.e. when $s$ exceeds 6 months. A pure UI scheme implies $b_{U A}=0$, while a pure UA scheme (indefinite payments) implies $b_{U A}=b_{U I}$.

The aim is to consider how changing the composition of this welfare system (i.e. changing $\left.b_{U I}, b_{U A}\right)$ affects labor market activity over the business cycle. Throughout, we shall only consider compensated changes so that the financing tax rate $\tau$ is the same in all simulated economies. Hence the difference in economic activity is not due to changes in the implied employment tax rate.

We consider a two state case, $N=2$, and $\pi_{1}=\pi_{2}=0.5$. Assuming a CobbDouglas matching function, so that $m(\theta)=A \theta^{\eta}$, the chosen parameter values are described in Table $1 .^{7}$

\footnotetext{
${ }^{7}$ Although we provide some justification for the parameters chosen, this is not meant to be a formal calibration exercise - assuming firms have all the bargaining power rules out a more explicit quantitative analysis.
} 


\begin{tabular}{|l|l|l|}
\hline$p$ & match productivity & 1 \\
\hline$l$ & flow value of leisure & 0.2 \\
\hline$a$ & flow vacancy cost & 100 \\
\hline$r$ & discount rate & 0.000107 \\
\hline$A$ & matching scale parameter & 0.0333 \\
\hline$\eta$ & $\begin{array}{l}\text { elasticity of the matching rate with } \\
\text { respect to the measure of vacancies }\end{array}$ & 0.5 \\
\hline$\lambda^{1}$ & job-destruction rate in booms & 0.000548 \\
\hline$\lambda^{2}$ & job-destruction rate in recessions & 0.000913 \\
\hline$\gamma$ & arrival rate of regime shock & 0.0044 \\
\hline
\end{tabular}

Table 1: Structural Parameters

The structural parameters are based on a time unit of one day. The match productivity is a normalization. The flow value of leisure is similar to numbers used elsewhere (e.g. Millard and Mortensen [1997]). The flow vacancy cost is chosen to generate reasonable average unemployment rates. It looks large because it has to capture all the capitalization costs of job creation and any subsequent non-labor production costs. $^{8}$ The discount rate is based on the $4 \%$ per annum number standard to the real business cycle literature. The matching elasticity and scale parameter are within the range found from estimates of the matching function (e.g. Blanchard and Diamond [1989]).

The job-destruction rates are based on an average job life of 5 years in booms and 3 years in recessions. This compares with the figure obtained by Cole and Rogerson

\footnotetext{
${ }^{8}$ Some models of this type (e.g. Albrecht and Vroman [2005]) use a parameter to represent a flow cost paid by the firm for the duration of the job, filled or vacant. Such an approach has the cosmetic benefit of a more realistic parameter value in simulations. But when firms have all the bargaining power, so that wages are determined purely by worker-side factors, this has little qualitative effect on the results.
} 
[1999] for the U.S. of 4.5 years. The value of $\gamma$ [and $\left.\pi^{i}=0.5\right]$ implies their preferred switching rate of 0.2 per quarter.

The baseline economy is a pure UA welfare system; i.e. $b_{U A}=b_{U I}$ and the level of payments is set where $b_{U A}=b_{U I}=0.2$. With $l=0.2$, this implies an equilibrium wage of 0.4 and hence a replacement rate of $50 \%$ in the baseline economy. Simulations find that the employment tax rate $\tau$ required for expected long-run budget balance is 0.018 ; i.e., $1.8 \%$ of total output.

Table 2 reports the simulation results. Each row describes a simulation with the same initial values $\left\{U_{0}, F_{0}, \lambda_{0}\right\}$ but different $b_{U I}$ and $b_{U A}$. For each $b_{U A}$, preliminary simulations were run to find the corresponding value of $b_{U I}$ so that the budget balancing tax rate $\tau$ remained neutral at 0.018 . Given each pair $\left(b_{U I}, b_{U A}\right)$ and the same initial values $\left\{U_{0}, F_{0}, \lambda_{0}\right\}$, the results described are for a simulation which is iterated over 100,000 days, the first 10,000 of which are dropped from the calculations (to avoid initial value distortions). Each set of results is computed using the same realized sequence of job destruction shocks.

\begin{tabular}{|l|l|l|l|l|l|l|l|l|}
\hline \multicolumn{2}{|l|}{ Benefits } & \multirow{2}{*}{$w_{0}$} & \multicolumn{2}{l|}{ Unemployment } & \multicolumn{2}{l|}{ Job Creation } & \multicolumn{2}{l|}{ Job Destruction } \\
\hline$b_{U I}$ & $b_{U A}$ & & $\begin{array}{r}\text { mean } \\
\%\end{array}$ & $\begin{array}{r}\text { st.dev. } \\
\times 100\end{array}$ & $\begin{array}{r}\text { mean } \\
\times 10^{4}\end{array}$ & $\begin{array}{r}\text { st.dev. } \\
\times 10^{4}\end{array}$ & $\begin{array}{r}\text { mean } \\
\times 10^{4}\end{array}$ & $\begin{array}{r}\text { st.dev. } \\
\times 10^{4}\end{array}$ \\
\hline 0.20 & 0.20 & 0.400 & 8.67 & 1.83 & 6.69 & 1.24 & 6.69 & 1.56 \\
\hline 0.23 & 0.15 & 0.352 & 7.99 & 1.72 & 6.75 & 1.28 & 6.75 & 1.58 \\
\hline 0.26 & 0.10 & 0.303 & 7.42 & 1.62 & 6.79 & 1.31 & 6.78 & 1.59 \\
\hline 0.28 & 0.05 & 0.254 & 6.92 & 1.54 & 6.83 & 1.34 & 6.83 & 1.61 \\
\hline 0.30 & 0 & 0.206 & 6.50 & 1.46 & 6.86 & 1.36 & 6.86 & 1.62 \\
\hline
\end{tabular}

Table 2: Unemployment, job creation and job destruction, $T=6$ Months.

The top row of Table 2 describes the baseline economy with a pure UA scheme (indefinite welfare payments) and a replacement rate of $50 \%$. The bottom describes 
a pure UI scheme where all welfare payments cease after 6 months. The intervening rows consider a 6 month UI scheme but with different levels of UA support. All require the same budget balancing tax rate $\tau=0.018$.

Column 4 describes how average unemployment varies across these welfare schemes and demonstrates that the pure UA scheme implies a significant increase in average unemployment. Column 3 shows why. $w^{H}(0)=w^{L}(0)=w_{0}$ is the wage a recently laid off worker negotiates. Although no more costly to operate (the required financing tax rate is the same), the pure UA scheme implies a large increase in the option value of remaining unemployed and hence higher negotiated wages (see Coles and Masters [2004] for a full discussion). Higher wages then lead to lower vacancy creation rates and higher unemployment.

For these parameter values, the constant UI scheme implies an average expected duration of unemployment of around 18 weeks (the U.K. in comparison has an average of around 26), while the pure UI scheme implies an average duration of around 13 weeks (as in the U.S.). But note that to obtain the same balancing employment tax rate, the value for $b_{U I}$ is necessarily high in the pure UI scheme $\left(b_{U I}=0.3\right.$ in the pure UI scheme, while $b_{U A}=b_{U I}=0.2$ in the pure UA scheme).

As equilibrium employment levels are higher in the pure UI case, the assumed job destruction process implies that the mean and variance of the number of jobs destroyed per period is greatest in the pure UI scheme (see the Job Destruction figures, columns 8 and 9 of Table 2). Ceteris paribus, this would imply the pure UI system generates greater unemployment variance over the cycle. Column 5 , however, reveals that the pure UI system also yields a lower variance of unemployment. This is due to the stabilization effects discussed above. In essence intergenerational transfers due to re-entitlement effects subsidize job creation rates in recessions, and so prevent unemployment becoming too high during extended periods of high job destruction, while dampening the increase in employment during booms.

Figure 2 depicts an impulse response function which describes how the average 


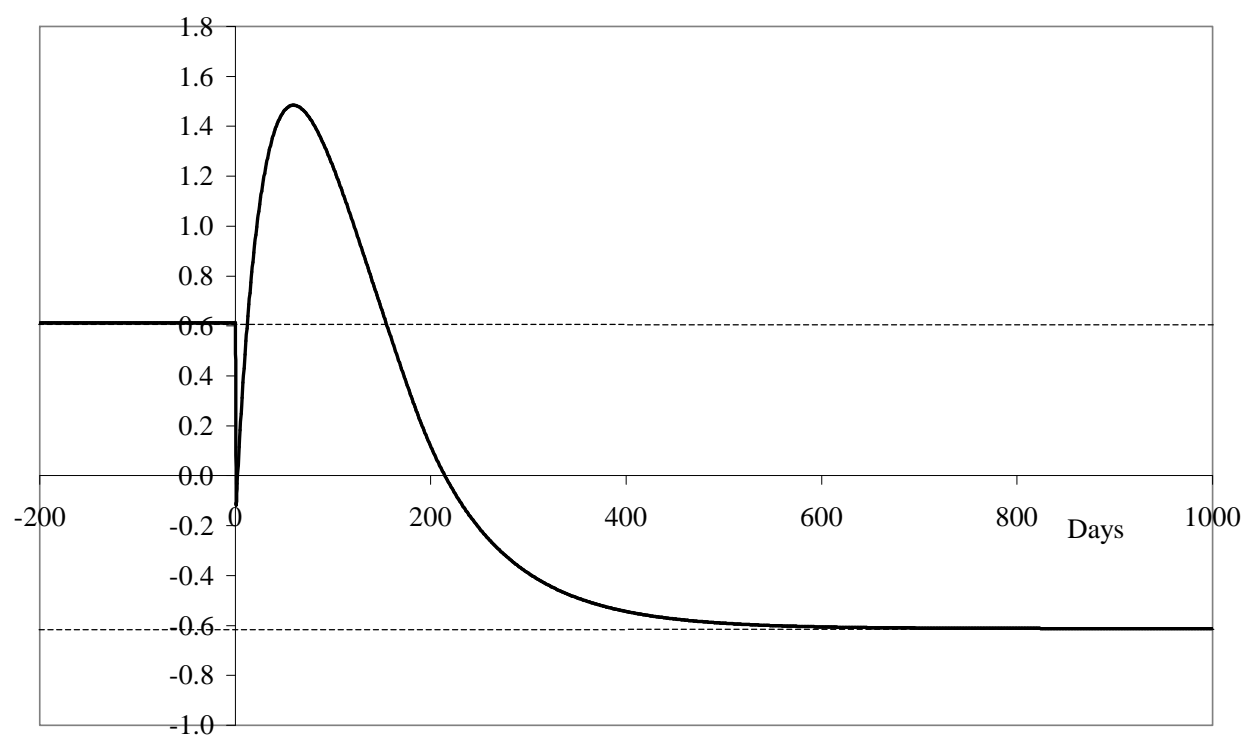

Figure 1: Impulse response: Percent deviation of average hiring wage from its (unconditional) expected value.

wage negotiated by workers hired at any point in time changes as the economy moves into recession. It has been constructed for the pure UI economy (bottom row) of Table 2. Prior to time 0 the economy is in the conditional steady-state associated with $\lambda=\lambda^{L}$ (a boom). At time $0, \lambda$ switches to $\lambda^{H}$ forever (though individuals in the model continue to expect the job destruction state to switch at rate $\gamma$.)

There is an initial downward jump in the average hiring wage at time 0 , which reflects the increased value of becoming re-entitled to future UI (see Proposition 1). The wave of newly laid-off workers, however, causes a decrease in the average uncompleted spell of unemployment. This feature of the data is well documented in the long-term unemployment literature (e.g. Machin and Manning [1999]). In our model, this fall in the average uncompleted spell leads, at least initially, to a spell of rising wages. This initial composition effect washes out at around 9 months.

In the longer-term, the economy moves toward a conditional steady-state associated with high job destruction. Not surprisingly this generates higher unemployment 
levels and longer unemployment spells. But re-entitlement effects, which enable hiring firms to extract rents from the worker's next future employer (potentially in a future boom), imply unemployment is not so high as it otherwise would have been. The overall effect is a reduction in the variance of unemployment over the cycle.

\section{Conclusion}

This paper has shown that when UI payments are duration dependent, re-entitlement effects in a non-competitive economy generate transfers from firms that hire in the future to currently hiring firms. Using an equilibrium matching framework, simulations find that a switch from a pure UA system to a pure 6-month UI system lowers both average unemployment and the variance of unemployment over the cycle.

A simple back-of-the-envelope calculation illustrates the potential magnitude of this stabilisation effect. Suppose that the UI program stops payments after 26 weeks of unemployment. Further suppose the business cycle is a two state phenomenon - the economy is either in recession with an average duration of unemployment equal to 18 weeks, or in a boom with an average duration of 8 weeks where each state is equally likely [i.e. the average spell is 13 weeks over the cycle]. In the recession, the mean remaining UI entitlement of a currently unemployed worker is 12 weeks more UI. ${ }^{9}$ Reflecting the worker's option value of remaining unemployed, the (average hiring) wage depends on the annuitised value of that remaining entitlement. But that hiring wage also reflects the worker's re-entitlement to future UI. Suppose then that when laid-off in the future, that layoff occurs in a boom. With average unemployment spells of 8 weeks in a boom, the mean remaining UI entitlement of a currently unemployed worker is 18 weeks. Hiring firms in booms offer higher wages to compensate for that entitlement, but those rents are essentially a transfer to the worker's previous employer. In this example, re-entitlement effects imply an average transfer of $18-12=6$

\footnotetext{
${ }^{9}$ This is computed using $\int_{0}^{\infty} \alpha_{w} e^{-\alpha_{w}} s \max [26-s, 0] d s$ with $\alpha_{w}=1 / 18$.
} 
weeks UI from firms that hire in booms to firms that hire in recessions. Assuming a $50 \%$ replacement rate and annuitising over an average employment spell of around 4 years (e.g. Cole and Rogerson [1999]) yields a 1.5\% wage subsidy. This is not a huge amount. Indeed the simulations show that average hiring wages do not move much over the cycle - hiring wages in the conditional steady state with low job destruction rates are only $1.2 \%$ higher than in the conditional steady state associated with high job destruction rates. Indeed the average employee wage hardly changes over the cycle. Nevertheless being a targeted hiring subsidy in recessions, simulations show that these transfers are effective in stabilising employment levels over the cycle.

For ease of exposition the paper has assumed the business cycle is driven by variations in job destruction rates (e.g. Davis and Haltiwanger [1992], Mortensen and Pissarides [1994]). Shimer [2005] challenges this view of the cycle. As our backof-the-envelope calculation reveals, however, what is important for our argument is that the average duration of unemployment is higher in recessions. Introducing productivity shocks complicates our model as renegotiation constraints might bind; e.g. the wage is renegotiated should productivity $p<w$. Of course when hiring, the firm and worker anticipate such renegotiations and, as the firm has all the bargaining power, the starting wage adjusts so that the firm still extracts all expected rents (see Postel-Vinay and Robin [2002a,b] for related arguments). Although wages then evolve stochastically during the lifetime of the job, the above insights continue to hold: re-entitlement effects imply a net subsidy to firms who hire in recessions.

\section{References}

D. Acemoglu [1997], "Training and Innovation in an Imperfect Labor Market", Review of Economic Studies, 64, 445-64.

D. Acemoglu and S. Pischke [1999], "The Structure of Wages and Investment in General Training", Journal of Political Economy, 107, 539-72. 
J. Albrecht and S. Vroman [2005], "Equilibrium Search with Time Varying Unemployment Benefits" Economic Journal, 115, 631-48.

K. Binmore, A. Rubinstein, and A. Wolinsky, [1986] "The Nash Bargaining Solution in Economic Modelling" Rand Journal of Economics, 17, 176-88.

O. Blanchard and P. Diamond, [1989] "The Beveridge Curve", Brookings Papers on Economic Activity, 1989:1, 1-76.

P. Cahuc and E. Lehmann [2000] "Should Unemployment Benefits Decrease with the Unemployment Spell?", Journal of Public Economics, 77, 135-53.

P. Cahuc, F. Postel-Vinay and J-M Robin[2005], "Wage Bargaining with On-the-job Search: Theory and Evidence", mimeo Universite de Paris I.

H. Cole and R. Rogerson [1999], "Can the Mortensen-Pissarides matching model match the business cycle facts?", International Economic Review, 40.4, 933-59.

M.G. Coles [2005] "Optimal Unemployment Insurance in a Matching Equilibrium: The Role of Congestion and Thick-Market Externalities." mimeo I.A.E (Barcelona)

M.G. Coles, and A. Masters [2004], "Duration Dependent UI payments in a Model of Equilibrium Unemployment" Economica, 71, 83-97.

M.G. Coles, and A. Masters [2005], "Optimal Unemployment Insurance in a Matching Equilibrium", forthcoming, Journal of Labor Economics.

C. Davidson and S. Woodbury [1997], "Optimal Unemployment Insurance", Journal of Public Economics, 64, 359-38\%.

S. Davis, and J. Haltiwanger [1992], "Gross Job Creation, Gross Job Destruction and Employment Reallocation", Quarterly Journal of Economics, 107, 819-63.

P. Fredriksson and B. Holmlund [2001] "Optimal Unemployment Insurance in Search Equilibrium", Journal of Labor Economics, 19, 370-399. 
R. Hall and P. Milgrom [2005] "The Limited Influence of Unemployment on the Wage Bargain," NBER Working Paper 11245.

H. Hopenhayn and J. Nicolini [1997] "Optimal Unemployment Insurance", Journal of Political Economy, 105, 412-38.

Y. Li and R. Wright, [1998] "Government Transaction Policy, Media of Exchange, and Prices" Journal of Economic Theory 81 290-313

S. Machin and A. Manning [1999], "The Causes and Consequences of Long Term Unemployment in Europe" in Ashenfelter, O. and Card, D. (eds) Handbook of Labor Economics volume 3. Amsterdam: Elsevier Science.

S. Millard and D. Mortensen [1997], "The Unemployment Effects of Labor Market policy: a comparison of the US and the UK", in D. Snower and G. de la Dehesa, eds., "Unemployment Policy: Government options for the Labor Market. Cambridge, UK: Cambridge University Press.

D. Mortensen [1977] "Unemployment Insurance and Job Search Decisions", Industrial and labor Relations Review, 30, 505-17.

D. Mortensen and E. Nagypal [2005] "More on Unemployment and Vacancy Fluctuations" mimeo Northwestern University

D. Mortensen and C. Pissarides [1994], "Job Destruction and Job Creation in the Theory of Unemployment", Review of Economic Studies, 61, 397-415.

OECD [2004] Benefits and Wages, OEDC indicators 2004, OECD: Washington D.C. C. Pissarides [2000], Equilibrium Unemployment Theory Cambridge, MA: MIT Press. F. Postel-Vinay and J.-M. Robin [2002a] "The Distribution of Earnings in an Equilibrium Search Model with State-Dependent Offers and Counter-Offers," International Economic Review, 43.4, 1-26. 
F. Postel-Vinay and J.-M. Robin [2002b] "Equilibrium Wage Dispersion with Worker and Employer Heterogeneity," Econometrica, 70.6, 2295-350.

S. Shavell and L. Weiss [1979] "The optimal Payment of Unemployment Insurance", Journal of Political Economy, 87, 1347-62.

R. Shimer [2003], "The Cyclical Behavior of Equilibrium Unemployment, Vacancies, and Wages: Evidence and Theory", mimeo University of Chicago.

G. van den Berg [1990] "Nonstationarity in Job Search Theory", Review of Economic Studies, 57, 255-77. 